\title{
De la lectura como práctica histórica en América Latina: la primera época colonial $y$ el siglo XIX
}

\author{
Reading as an Historical Practice in Latin America: The \\ First Colonial Period and the $19 \mathrm{t}^{\mathrm{h}}$ Century \\ Da leitura como prática histórica na América Latina: \\ a primeira época colonial e o século XIX
}

\section{Juan Poblete}

UNIVERSITY OF CALIFORNIA AT SANTA CRUZ, ESTADOS UNIDOS

Profesor de Literatura y Estudios Culturales Latinoamericanos en la

Universidad de California, Santa Cruz, Estados Unidos. PhD Duke

University. Es autor de Literatura chilena del siglo XIX: entre públicos

lectores y figuras autoriales (Santiago de Chile: Cuarto Propio, 2003);

editor de Critical Latin American and Latino Studies (Minneapolis:

University of Minessota Press, 2003) y co-editor de Andrés Bello (con

Beatriz González-Stephan, IILI, 2009), Redrawing The Nation: National

Identities in Latin/o American Comics (con Héctor Fernández-L'Hoeste,

Nueva York: Palgrave, 2009), Desdén al infortunio: sujeto, comunicación y

público en la narrativa de Pedro Lemebel (con Fernando Blanco, Santiago

de Chile: Cuarto Propio, 2010), Sports and Nationalism in Latin America

(con Héctor Fernández L'Hoeste y Robert McKee-Irwin, Nueva York:

Palgrave, 2015), y Humor in Latin American Cinema (con Juana Suárez,

Nueva York: Palgrave, 2015). Correo electrónico:jpoblete@ucsc.edu

Artículo de reflexión

Este artículo se publicó originalmente como "Reading as a Historical Practice in Latin America: the First Colonial Period and the Nineteenth Century" en Latin American Literary Cultures: A Comparative History of Cultural Formations. Kadir, Djelal y Mario J. Valdés (editores). Volumen 1. Oxford: Oxford University Press, 2004: 178-192. Impreso. Documento accesible en línea desde la siguiente dirección: http://revistas.javeriana.edu.co 


\section{Resumen}

El artículo propone una reconstrucción teóricohistórica del lugar de la lectura y los lectores en dos momentos de la historia de la cultura latinoamericana. Proyecta, entonces, a partir de los casos mexicanos y del Cono Sur algunas proposiciones generalizables para la determinación de dos macromomentos (el colonizador y el decimonónico) en el estudio histórico de la lectura en

América Latina. Se destacan, por una parte, las relaciones entre Iglesia, Estado y lectores; y, por otra, las relaciones entre estos últimos y los textos. En ambos casos lo que se negocia y disputa socialmente son las formas de autoridad y legitimidad relativa de cada uno de los actores involucrados en la determinación del sentido, función y destino de los textos culturales. Sostengo, además, que estas relaciones son no solo un aspecto más sino una parte fundamental de las formas de existencia y producción de la literatura en el continente.

Palabras clave: Lectura; lectores; Iglesia; Estado; públicos

\section{Abstract}

This article proposes

a theoretical-historical reconstruction of the role of reading and readers at two specific moments in the history of culture in Latin America. Focusing on the contexts of Mexico and the Southern Cone, it projects several generalizable propositions for the determination of two macro moments (that of colonization and the 19th century) in the historical study of reading in Latin America. The article first emphasizes the relation between the church, the state and readers and subsequently examines the relation between these groups and the written word. In both cases, what was socially negotiated and disputed were the forms of relative authority and legitimacy pertaining to each of these actorgroups engaged in determining the meaning, function and destination of cultural texts. The article also argues that church, state and reader relations were not merely one more aspect of the forms of existence and production of literature on the continent but a fundamental dimension of those forms.

Keywords: Reading; Readers; Church; State; Public Reader

\section{Resumo}

$\mathrm{O}$ artigo propõe uma reconstrução teórico-histórica do lugar da leitura e os leitores em dois momentos da história da cultura latinoamericana. Projeta, então, a partir dos casos mexicanos e do Cone Sul algumas proposições generalizáveis para a determinação de dois macromomentos (o colonizador e o decimonônico) no estudo histórico da leitura na América Latina. Destacam-se, por uma parte, as relações entre Igreja, Estado e leitores; e, por outra, as relações entre estes últimos e os textos. Em ambos os casos, o que é negociado e disputado socialmente são as formas de autoridade e legitimidade relativa de cada um dos atores envolvidos na determinação do sentido, função e destino dos textos culturais. Defendo, aliás, que estas relações nem são apenas um aspecto mais senão parte fundamental das formas de existência e produção da literatura no continente.

Palavras-chave: Leitura; leitores; Igreja; Estado; públicos

\section{Cómo citar este artículo:}

Poblete, Juan. "De la lectura como práctica histórica en América Latina: la primera época colonial y el siglo XIX". Cuadernos de Literatura 20.39 (2016): 57-94. http://dx.doi.org/10.11144/Javeriana.cl20-39.lpha 
¿CUÁL HA S ID o el lugar de la lectura en las revisiones teóricas que solemos englobar bajo el nombre de estudios culturales latinoamericanos? ¿Qué aportes y cambios ha traído el énfasis de los estudios culturales en nociones tales como producción-recepción, consumo, resemantización, reapropiación, etc.? ¿Cómo se ha beneficiado nuestra percepción del proceso de la producción social del objeto textual, con estos avances teóricos? No me propongo aquí ofrecer una visión comprensiva que intente responder a estas y a otras preguntas de esta naturaleza. Más bien me interesa usarlas como marco conceptual para proponer una reconstrucción teórico-histórica del lugar de la lectura y los lectores en dos momentos de la historia de la cultura latinoamericana. Obviamente, tanto el estado de la investigación como los límites de este artículo (para no decir nada de los personales) conspirarán para hacer de este solo un primer y provisorio acercamiento a una cuestión que estimo fundamental.

Uno de los aportes claves de los estudios culturales en el área latinoamericana ha sido, al menos al nivel teórico, la revalorización de los procesos de producción de la significación por parte de los sujetos receptores de discursos. Jesús MartínBarbero ha resumido este cambio teórico general destacando el paso del estudio de los medios (determinismo tecnológico o político) a las mediaciones en la producción del sentido de las comunicaciones sociales. Otra forma más específica de aludir a esto es enfatizar el desplazamiento desde el análisis del discurso y su significación intrínseca hacia el análisis de la producción social del sentido:

La comunicación no se agota en el mensaje. Después de todo el tiempo que le dediqué a la semiótica me di cuenta que pensar la comunicación desde el análisis del discurso nos condenaba a pensar la significación, pero no el sentido, porque para poder hablar del sentido de la comunicación hay que hablar del sentido que la comunicación tiene para la gente. (Martín-Barbero 1995, 16)

Estos procesos colectivos de lucha por la definición de la semiosis social tienen una larga historia en el continente y forman parte importante de la "historia de la constitución de lo cultural" mismo en América Latina (31). Aquí serán estudiados a propósito de las formas históricamente variables de las prácticas de recepción o lectura concebidas como maneras de producción cultural.

Mi hipótesis es doble y sostiene que, por un lado, las relaciones entre el Estado y la Iglesia en relación a la lectura y a la formación de públicos lectores y, por otro, las relaciones entre público lector y texto, varían a lo largo de la historia latinoamericana. Sostengo, además, que estas relaciones son no solo un aspecto más sino una parte fundamental de las formas de existencia y producción de la literatura en el continente. 
Más que la demostración de una tesis, debo aclarar, este ensayo ha querido ser la formulación de un programa de trabajo e investigación en el que, al mismo tiempo que se aprovechan algunos acercamientos anteriores, se vislumbran las muchas tareas aún por realizar. Entre aquellos acercamientos se cuentan el análisis discursivo formal, es decir, las relaciones jerárquicas de diferentes discursos al interior de un texto (Horta Nunes); el análisis ideológico e histórico (Mignolo, Lienhard); los espacios textuales que incorporan, permiten y predicen las operaciones del lector (Eco, Goodrich); las representaciones de la lectura al interior de los textos narrativos (Bremer); los discursos sociales acerca de la conveniencia o inconveniencia de la novela (Poblete 1999), etc. Finalmente, entre las investigaciones que es preciso extender a todo el continente se hallan las que en México ha avanzado el Seminario de Historia de la Educación. En ellas se estudian los procesos de aprendizaje y enseñanza de la lectura y, en menor medida, las formas históricas y las variaciones de los actos de lectura mismos (véase su obra Historia de la lectura en México).

Dentro de los límites del presente ensayo, entonces, se proyectan a partir de los casos mexicano y del Cono Sur algunas proposiciones generalizables para la determinación de dos macromomentos (el colonizador y el decimonónico) en el estudio histórico de la lectura en América Latina. Allí se destacan, repito, por una parte las relaciones entre Iglesia, Estado y lectores; por otra, las relaciones entre estos últimos y los textos. En ambos casos lo que se negocia y disputa socialmente son las formas de autoridad y legitimidad relativa de cada uno de los actores involucrados en la determinación del sentido, función y destino de los textos culturales. Este proceso de disputa semiótica sobre los textos, esta determinación de los espacios socialmente legibles (de Certeau) y de las prácticas que los actualizan (Bennett), tiene como precondición el de su acceso y circulación. En el primer momento colonizador, la Iglesia pretende cortar el acceso de las poblaciones indígenas a sus fuentes de producción cultural (la memoria escrita y oral transmitida y producida en el diálogo madre-hijos, sacerdotes o intelectuales nativos-población india en general) para reemplazarlas por nuevos ritos, textos y procesos comunicacionales de carácter evangelizador. En el segundo momento estudiado, la multiplicación y la circulación de la producción editorial y periodística abre un nuevo espacio-agente: el del mercado. A diferencia de los procesos comunicacionales anteriores que, aunque producen sujetos súbditos y fieles, son fuertemente colectivos en orientación, los que tienen por escenario el mercado de los países postcoloniales en el siglo XIX son vividos y ofrecen la ilusión de ser procesos individuales de subjetivación. En ellos, el lector ahora silente y privado vive su propia relación de distancia relativa con el texto como 
un proceso eminentemente personal. Aunque obviamente ambos tipos de formaciones lectoras son colectivos y sociales por definición, en ellos el modo de relación lector-texto ofrece dos énfasis opuestos. A estos debe agregarse, además, el mercado de impresos populares sobre el cual volveremos luego. En todos estos casos una cierta economía de la circulación de textos preside las formas de asignación de sentido que determinan sus posibilidades de significación.

\section{Lectura, producción, texto}

Para empezar debemos realizar, aunque más no sea brevemente, una operación preliminar: reconceptualizar la lectura como práctica cultural. Las palabras descalificadoras de Terry Eagleton en un ensayo irónicamente titulado "The Revolt of the Reader" sobre los estudios de la recepción, reflejan bien el escepticismo y aun el desdén con que un sector de la crítica tradicional (marxista y de otros cuños) los ha recibido: "The growth of the Reader's Liberation Movement (RLM) over the past few decades has struck a decisive blow for oppressed readers everywhere, brutally proletarianized as they have been by the authorial class" (181). Después de caracterizar la historia de los estudios de la recepción distinguiendo con humor sus alas derecha, centrista y de izquierda, Eagleton concluye: "A socialist criticism is not primarily concerned with the consumer's revolution. Its task is to take over the means of production" (184).

Dana Polan ha llamado a esto la pervivencia en cierto marxismo contemporáneo de una visión romántica de la producción que supone que, tras este momento prístino y originario, el proceso social de circulación e intercambio de bienes y de sentidos es una suerte de decadencia y caída (264). Los estudios más recientes sobre la lectura han tratado, precisamente, de remar contra condenas "materialistas" tradicionales como las de Eagleton sosteniendo, por el contrario, que la recepción - entendida como una actividad colectiva y culturalmente determinada - es uno de los aspectos más importantes del proceso de producción social del sentido. Lejos de ser el espejismo de una revolución de consumidores, la recepción ha aparecido como el momento propiamente comunicacional en la circulación de discursos sociales. Michel de Certeau, por ejemplo, ha señalado: "The efficiency of production implies the inertia of consumption-as-a-receptacle [...] By challenging 'consumption' as it is conceived and (of course) confirmed by these authorial enterprises, we may be able to discover creativity where it has been denied that any exists..." (167).

En la misma línea, Néstor García Canclini preguntando "si al consumir no estamos haciendo algo que sustenta, nutre y hasta cierto punto constituye un nuevo modo de ser ciudadanos", ha respondido: "Consumir es participar en un 
escenario de disputas por aquello que la sociedad produce y por las maneras de usarlo" (1995 27 y 44). Recuperando los aspectos colectivos y productivos de la recepción, ha creído posible, asimismo, afirmar:

Una nación, por ejemplo, se define poco a esta altura por los límites territoriales o por su historia política. Más bien sobrevive como una comunidad interpretativa de consumidores, cuyos hábitos tradicionales —alimentarios, lingüísticos- los llevan a relacionarse de un modo peculiar con los objetos y la información circulante en las redes internacionales. (1995 50-51)

Jesús Martín-Barbero ha resaltado, por su parte, lo inadecuado que resulta el análisis tradicional de contenidos y estilos para la comprensión de muchos géneros de la comunicación masiva y popular. Centrarse exclusivamente en el texto o en las formas de producción autorial es perder de vista que en las telenovelas, por ejemplo, lo que más importa son los espacios de resignificación que sobre ellas operan los receptores en diálogo: "...la idea que las mujeres se hacen de la telenovela varía mucho en la medida que la van contando a las amigas y vecinas [...] la telenovela no significa tanto por lo que la gente ve directamente sino por todo este diálogo. La telenovela tiene éxito porque le sirve a la gente para hablar de su vida" (1995 56).

Finalmente, Tony Bennett ha establecido lo que no es sino una propiedad de todo texto: su pertenencia a una esfera pública o política dominada por determinadas formaciones discursivas y lectoras que contribuyen de manera decisiva a la producción de sus sentidos. La idea de formación lectora recoge el aporte de Michel Foucault sobre las formaciones discursivas. Foucault define esta última como una cierta regularidad de relaciones entre discursos que coagulan en un momento y en un espacio históricos determinados para ofrecer la imagen ilusoria (pero legitimada) de la totalidad de los discursos sociales (Foucault 1972). Por formación lectora, por su parte, Bennett entiende "a set of discoursive and intertextual determinations which organise and animate the practice of reading, connecting texts and readers in specific relations to one another in constituting readers as readings subjects of particular types and texts as objects-to-be-read in particular ways" (1987 70). Conviene destacar aquí que esta definición presupone que tanto el texto como la lectura son construidos social e históricamente. Es decir, que no hablamos de un mismo texto que recibe diferentes interpretaciones a lo largo de la historia, sino de textos y lecturas que varían de maneras similares y como producto de una actualización en un aquí y ahora de sus relaciones oposicionales con otros textos (formación discursiva) y otras prácticas de lectura (formación lectora). 
Todo ello implica que la literatura no se liga, o por lo menos no principalmente, a las formas de poder social a través de una relación de tipo representacional-ideológico, como quería el marxismo tradicional. La literatura no es, entonces, simple y directamente una ideología cuya función principal sería la producción de sujetos receptivos de sus mensajes pacificadores. Son, en cambio, los mecanismos sociales e institucionales a través de los cuales se usan, se despliegan socialmente determinados textos los que constituyen a la literatura en sus formas concretas y variables de existencia social (Bennett 1990).

Dentro de esta línea de análisis, "leer" un texto es construirlo, es hacerlo significar dentro de un espacio social. Si todo texto, entonces, literario o no, no puede sino participar de una semiosis que es en principio ilimitada, una de las cosas que importa estudiar históricamente es de qué forma "se leen" los textos dentro de los límites y posibilidades marcadas por las prácticas y los espacios que los procedimientos institucionales construyen en un momento determinado.

Aunque solo analizaré con algún detalle dos macromomentos en la historia de la lectura en el continente, me interesaría ahora señalar, al pasar y a manera de contexto, una periodización de momentos que preceden, se incluyen o suceden a los dos aquí comentados. Habría una primera etapa que correspondería al desarrollo paralelo e independiente de las formas de literacy en la América precolombina y en Europa. En el segundo momento la ideología del libro y de la letra se enfrenta a las formas desde entonces aparentemente subordinadas de los saberes indígenas en el continente. Esta será la instancia que aquí estudiaremos como colonizadora. En tercer lugar, tendríamos el momento de emergencia de una cultura popular barroca y católica en los siglos XVI y XVII (Morandé). En cuarto lugar, el momento borbónico en el siglo XVIII en que el Estado moderno asoma su cabeza en el continente para disputarle a la Iglesia su hegemonía en la producción de formas de subjetivación ciudadana. El quinto momento será el decimonónico, en que emerge una cultura protomasiva y protomassmediática que coincide con la emergencia política del problema de las culturas nacionales, problema considerado tanto por los intelectuales de estado como por los que luchan desde fuera de él. En esta etapa, la cultura extendida y popular de los periódicos, la pérdida de la sacralidad del libro, la mecanización y abaratamiento de su producción y la entrada en los ritmos del consumo cultural tendencialmente masivo, serán las notas dominantes. En un sexto momento, esta cultura nacional se masifica efectiva y realmente bajo la inspiración y la fuerza, las más de las veces, de campañas culturales propiciadas por el Estado como parte de sus esfuerzos de construcción de hegemonía en tiempos mesocráticos y populares. Esta será la época de los populismos y de lo nacional-popular. 
El último momento sería el de la transnacionalización de los medios de comunicación y de algunas de las formas del consumo y la producción cultural. En él entran en crisis y se enfrentan a importantes desafíos algunas de las formas básicas de territorialización y subjetivación impulsadas por los estados nacionales y la Iglesia católica y, con ellas, las formaciones discursivas y lectoras que habían caracterizado la modernidad latinoamericana. La globalización impone así una reconsideración de las prácticas tradicionales para la formación de sujetos ciudadanos y de fieles, las formas de producción y de acumulación de capital cultural, las formas de jerarquización y por ende la rentabilidad simbólica de las distintas esferas culturales, etc.

\section{El momento colonizador}

Contrariamente a la percepción habitual, Rolena Adorno sostiene, destacando los aportes de Irving Leonard y otros estudiosos al tema en la primera época colonial (lo que aquí llamamos el momento colonizador para distinguirlo del colonial de los siglos XVII y XVIII), que la Iglesia y más en concreto la Inquisición, que era su brazo censurador, parecen haberse desentendido de la prohibición de libros de ficción simplemente porque este tipo de libros carecía de contenidos dogmáticos (Adorno 1992). El estado español, en cambio, al menos al nivel de las prohibiciones (decretos de 1531 y 1543) aunque sus resultados prácticos deban ser discutidos, sí se ocupó de la necesidad de prohibir la lectura de ficción literaria por razones que podríamos llamar platónicas: enciende la imaginación, persuade, seduce y estimula. Sin embargo, incluso aquellos dos decretos reales justificaban la prohibición de los libros de ficción sobre la base de que corromperían no tanto a los soldados como a los indios. Así, el decreto de la reina en 1531 para los oficiales de la Casa de Contratación de Sevilla que regulaban el paso de mercancías a América, señalaba (en versión que modernizo):

He sido informada que pasan a las Indias muchos libros de Romance, de historias vanas y de profanidad como son el Amadís y otros de esta calidad y que por este es mal ejercicio para los indios y cosa en que no es bien que se ocupen ni lean por ende yo os mando que de aquí en adelante no consintáis ni deis lugar a persona alguna pasar a las Indias libros ningunos de historias y cosas profanas salvo tocante a la religión cristiana... (Torre Revello 3)

A pesar de ello, en la práctica histórica de este primer período, la censura de la lectura de libros de ficción pareció no preocupar mayormente a las autoridades eclesiásticas o bien carecer de eficacia concreta (Torre Revello 40; Leal xlii). No podría decirse lo mismo de las lecturas religiosas que formaban parte de su 
esfuerzo evangelizador (y, por ende, de su misión legitimadora) entre las comunidades de indios. Como veremos enseguida, en este terreno la Iglesia empeñó toda su energía y celo en la llamada persecución y erradicación de idolatrías. Andando el tiempo, en el siglo XIX, la Iglesia descubriría que dada la expansión de las formas de reproducción masiva de obras de ficción, este era también, y ahora principalmente, un espacio en que su propia hegemonía sobre importantes sectores sociales estaba en entredicho.

En la primera Colonia, entonces, la subjetividad que desde el punto de vista eclesiástico necesitaba ser conquistada y de hecho construida era la de los indios (Gruzinski 186-228). Este proceso de formación de subjetividades tiene dos aspectos. El negativo se basa en el control del material impreso (que incluye tanto la persecución de idolatrías rituales como la de los discursos en que se guarda la parte formalizada de la memoria indígena) y en el cercenamiento de la relación maternal de oralidad a través de la imposición de una entidad tercera, la Iglesia misma que asume las funciones de madre-colectiva. En su lado positivo, la nueva subjetivación se funda en las prácticas de formación de intelectuales y en la labor de mediación general que los sacerdotes realizan en el centro del proceso de semiosis social que busca transformar a los indios en buenos cristianos, es decir, en seres trabajadores, obedientes y católicos.

El primer aspecto (negativo) de este proceso tiene su fundamento en la fetichización de la escritura (Lienhard) o ideología del Libro y la Letra (Mignolo 1995). Martin Lienhard ha señalado:

La destrucción del sistema antiguo, basado en una articulación equilibrada entre palabra archivadora y palabra viva, y la imposición arbitraria de un nuevo sistema en el cual el predominio absoluto de la "divina" escritura europea relega a la ilegalidad las diabólicas "escrituras" antiguas, marginando al mismo tiempo la comunicación oral, constituirá el trasfondo sobre el cual surge la literatura "latinoamericana". (41)

Con ello Lienhard alude a lo que arriba llamamos la configuración de una formación discursiva en las sociedades prehispánicas. Tanto los glifos mesoamericanos como los quipus quechuas habrían sido esencialmente formas administrativas para el almacenamiento de datos y para la fijación de un saber ya constituido y archivable. El complemento natural de estos discursos escritos era la oralidad. En esta forma oral se elaboraban los discursos concernientes a la tradición y la historia como narraciones y las reflexiones que solemos englobar bajo el nombre de filosofía. Allí se acumulaba, reproducía y transformaba una memoria social activa. Más adelante volveré sobre esta complementariedad de oralidad y escritura en las culturas prehispánicas. 
Para desplazar y reposicionar dicha formación discursiva y lectora indígena, los misioneros llevaron a cabo el doble y paradójico proceso de extirpación y preservación de los discursos orales y escritos indígenas en la escritura indo-hispánica que constituye el corpus de recopilaciones que culminan en la obra de Bernardino de Sahagún. Esta escritura aparece como un antecedente de la etnoficción indigenista de los siglos XIX y XX en que se fabrica un discurso étnico artificial del Otro destinado a un público lector ajeno a la cultura "exótica" (Lienhard 190). A diferencia de este último discurso, sin embargo, las recopilaciones y crónicas del momento colonizador fueron, finalmente, incapaces de contener las posibilidades semióticas subversivas que los discursos indígenas, que traducían y alteraban, significaban potencialmente para las reinterpretaciones de los lectores autóctonos:

El carácter a fin de cuentas "explosivo" de las crónicas contaminadas por el discurso indígena explica, sin duda, la censura que se abatió sobre ellas. Casi ninguna de ellas por excelentes que fueran sus motivaciones oficiales (extirpación de idolatrías, demostración de la barbarie indígena...) llega a imprimirse en su época. (Lienhard 52)

Describiendo los mecanismos discursivos que ponen en contacto la tradición oral indígena brasileña con los discursos escritos europeos, José Horta Nunes ha estudiado - utilizando sobre todo las armas del análisis discursivo- el lugar que al lector propiamente brasileño, es decir, al híbrido heredero de aquellas dos discursividades, se le construye y prepara en esta tradición textual:

[...] os missionários introduzem una prática de leitura orientada pelos objetivos de catequese e colonização. Sua atividade desenrolasse por um lado na prática do discurso de conversação, nas pregações, conferencias etc.; por outro na produção de conhecimentos sobre o Novo Mundo, seja na forma de relatos, seja na de catecismos, gramáticas, dicionários. Esse conjunto de atividades e de objetos simbólicos determina a construção de una posição para o leitor no Brasil, no caminho entre a discursividade do europeu e a do índio. (Horta Nunes 103)

Esta posición del lector brasileño se organizará en torno a un mecanismo semiótico que se quiere total y omnicomprensivo. En él se crea el espacio para que a cada pregunta del discurso oral indígena corresponda una y solo una lectura o interpretación correcta en clave cristiana dentro del discurso escrito catequizador: "A representação das situações de contato pelos missionários mostra-se de forma de estruturar as perguntas e respostas, fixando os sentidos a serem lidos, e interditando a produção de outras interpretações" (102). 
Para realizar esta labor los misioneros llevan a cabo dos operaciones fundamentales: penetran, por un lado, el discurso oral indígena por la vía de representaciones escritas de diálogos y coloquios entre indios y misioneros en los que el primero es traducido y respondido a cabalidad por el segundo. Es decir, representan por escrito las situaciones de oralidad características de la enseñanza y el aprendizaje autóctono para reinscribirlas en el espacio cristiano. Por otro lado, los misioneros producen conocimientos, gramáticas y diccionarios en que esta misma operación de modelización traductora de un discurso por el otro se formaliza, a la vez que se torna en instrumento disponible para la mejor realización de la empresa de adoctrinamiento.

A través de estos mecanismos textuales se intenta anticipar y controlar las respuestas de interpretación semiótica del indio. Debe destacarse que el control de esta semiosis ocurre en el mismo momento en que se le da voz al discurso oral indígena. Para ello este discurso está artificialmente constreñido a una serie de preguntas-respuestas que, aunque amplias, limitan el alcance de lo enunciable y pertinente en un espacio que, si bien es formalmente dialógico, corresponde en rigor a una estructura altamente jerarquizada. Tal vez el ejemplo más famoso sea el de Los coloquios de los doce primeros misioneros de México de fray Bernardino de Sahagún que Pilar Gonzalbo califica de "algo así como una "suma contra gentiles', planeada y desarrollada para el mundo nahua" (Gonzalbo 19).

La Real Cédula de la Reina al virrey de México en 1536, acerca de la prohibición de lectura de obras de ficción, ratifica la importancia estratégica de dicha interdicción. Además de preocuparse por los efectos morales directos de esas ficciones, lo que le intranquilizaba a la soberana eran los que podríamos llamar efectos ideológicos indirectos que esas lecturas podrían producir:

Algunos días ha que el Emperador y Rey proveyó que no se llevasen a esas partes libros de Romance de materias profanas y fábulas porque los indios que supiesen leer no se diesen a ellos dejando los libros de buena y sana doctrina y leyéndolos no aprendiesen en ellos malas costumbres y también porque desde que supiesen que aquellos libros de historias vanas habían sido compuestos sin haber pasado, no perdiesen la autoridad y crédito nuestra sagrada Escritura y otros libros de doctores santos. Creyendo como gente no arraigada en la Fe que todos nuestros libros eran de un autoridad y manera. (Torre Revello iv)

Es decir, si la lectura y circulación de ficción debía ser prohibida, la razón más importante era el contagio que dentro de la formación discursiva colonial producirían dichas obras. De una manera mucho más corrosiva para los designios imperiales que las representaciones directas de actos moralmente 
reprobables, las obras ficticias, como discursos que compartían el espacio con los de la adoctrinación y conversión católicas, podían subvertir en el imaginario indígena, pensaba la reina, el status y el efecto ideológico superior de los otros discursos escritos que el llamado fetichismo escriturario intentaba imponer y reproducir en los receptores indios. La apertura hacia esa potencial subversión de los códigos y prácticas educativas de los religiosos españoles, sin embargo, estaba permanentemente presente dada la imposibilidad de hacer verdadera y efectiva tabula rasa de las formas de discurso y de producción del sentido de las culturas prehispánicas.

\section{La semiosis colonial}

Walter Mignolo ha estudiado en profundidad tanto lo que llama "la cuestión de la letra" y de la escritura (que Lienhard denomina fetichismo de la escritura), como los procesos que denomina de "semiosis colonial". La ideología de la letra y del libro consiste fundamentalmente en confundir la escritura alfabética y el libro, que no son más que instrumentos para la preservación y comunicación de conocimientos sociales, con la esencia y existencia de dichos conocimientos. De este modo los conquistadores adscribieron la "ausencia" de libros y letras en las culturas nativas a una supuesta falta de civilización y de historia. En este esquema la "falta de letras" equivalía a la "falta de historia" y la oralidad a la prehistoria. Se les negaba así a las culturas prehispánicas el derecho a coexistir como tales con las europeas en la historia de la humanidad y se las señalaba de inmediato como pertenecientes a un tiempo y espacio destinado a ser conquistado y superado por la verdad de la historia escrita de la Cristiandad. En oposición a este prejuicio hoy todavía abundante, Mignolo propone una comprensión de las formaciones discursivas y receptoras indígenas que parta de la afirmación de que la oralidad no es un "antecedente" de la literacy sino un sistema equivalente de práctica y conceptualización de discursos socialmente relevantes.

Para nuestros propósitos aquí, interesa destacar en esas formaciones discursivas prehispánicas la coexistencia de géneros discursivos formales en prosa (los tlahtolli y, en especial, los teotlahtolli y huehuetlahtolli del discurso religioso y de la sabiduría de los ancianos, respectivamente) con otras formas de discurso poético en que tanto la emisión como la recepción involucran la participación del cuerpo de los comunicantes. Estos son los cuicatl o canto-poesía en que el discurso oral es acompañado de música y de ritmo (León Portilla, 1996 31-41). Luego volveremos sobre la naturaleza colectiva y corporal de estos procesos.

Aprovechando el aporte de especialistas y etnógrafos, Mignolo ha propuesto el estudio de "una significativa producción literaria oral y, también, de una 
conceptualización de ella que parta de una 'filosofía del lenguaje" centrada en la oralidad y no en la escritura (Mignolo, 1993 552). Como en el caso de las varias versiones de los libros de Chilam Balam recogidos y preservados durante siglos por diversas comunidades mayas, estaríamos aquí en presencia de formas de hibridación discursiva entre las tradiciones prehispánicas y las europeas. En ellas:

[...] the European script that the friars were so eager to transmit in order to be more effective in the Christianization of the natives was used by Amerindians to stabilize their past, to adapt themselves to the present, to transmit their traditions to future generations and, in summary, to resist the colonization of language. (Mignolo, 1995 207)

De este modo comenzaban formas de adaptación e hibridación de las culturas amerindias y americanas, formas de resemantización de discursos metropolitanos y aprovechamientos estratégicos de las tecnologías disponibles, que han caracterizado la vida y los procesos de re/producción cultural en América Latina (Adorno, 1996 35-37; García Canclini 199o). Para estudiar estos procesos históricos de encuentros de formaciones discursivas y lectoras en posiciones desiguales de poder político, militar y (por ende) epistemológico, Mignolo ha acuñado la expresión "semiosis colonial". Con ella, se propone superar la ideología del libro y de la letra, al cuestionar el lugar epistemológico del sujeto cognoscente occidental y la jerarquización de lugares asignados en una visión evolucionista y eurocéntrica, con sistemas realmente coexistentes y equivalentes de codificación y transmisión de información social y culturalmente relevante. Estos sistemas, los amerindios (fundados en la oralidad y en formas alternativas de representación gráfica) y el europeo (centrado en la escritura y el libro), entraron muy pronto en América en una gran variedad de relaciones de interferencia e hibridación para cuyo estudio la "semiosis colonial" parece la expresión más adecuada (Mignolo, 1995 1-25).

Pocas personas han contribuido a la comprensión de este proceso de producción cultural indígena mestiza o hibridizada, en el primer momento colonizador, con la claridad y la sutileza de Serge Gruzinski. En su obra se percibe la importancia de comprender, en sus facetas a menudo contradictorias y complejas, las formas históricas de constitución de un imaginario cultural. Para nuestros efectos aquí, interesa destacar su énfasis en las formas de apropiación y resemantización cultural que llevan a cabo, de maneras diversas, los distintos sectores que componen una entidad subalterna. Este acento descubre en las formas de subjetivación, en los mecanismos de lectura y de apropiación, otras tantas formas de producir cultura que suelen permanecer invisibles para el radar letrado centrado en la individualidad productiva del autor singular. 
En lo fundamental Gruzinski señala la existencia de dos sub-momentos en la historia de este proceso de aculturación colonial. En el primero, la empresa educativa y religiosa de los misioneros intentó reproducir las divisiones socioculturales prehispánicas y aprovecharlas en beneficio de su labor evangelizadora. Para ello se dedicó, por un lado, a formar dos tipos de sujetos-receptores: los de élite que poseerían todos los elementos de producción semiótica (lecto-escritura) en una cultura bilingüe o aún multilingüe (nahuatl, latín, español) y los de la masa que estaban destinados a recibir en la lengua nativa las explicaciones de los sacerdotes. Reproducían así la estratificación constitutiva de las escuelas mexicas precolombinas: calmécac o escuelas de nobles y telpochcalli o escuelas de plebeyos (López Austin 33). Por otro lado, los misioneros requirieron y desarrollaron formas discursivas mixtas en que se aprovechaban los géneros de la cultura oral prehispánica para darles una forma y un contenido escrito y cristianizado. Se recuperaron así los antiguos cantares en beneficio de la enseñanza del canto llano y gregoriano, a la vez que se reciclaban y cristianizaban los convencionalismos estilísticos característicos de la discursividad indígena (flores, mariposas, plumas de quetzal) (Gruzinski). Del mismo modo, y al menos en el siglo XVI, se desarrollaron aunque en menor cantidad formas mixtas de catecismos y confesiones jeroglíficas en que la doctrina cristiana y los pecados eran representados gráficamente siguiendo las convenciones prehispánicas.

Se generaron así tanto el llamado Humanismo indio de la Nueva España representado por el Colegio de Tlatelolco — "el colegio de los gramáticos indios" en frase de su fundador, fray Juan de Zumárraga (Osorio XXII) - como el nahuatl de Iglesia que a partir del segundo sub-momento histórico propuesto por Gruzinski, había de "regir las relaciones de los indios con el clero y con los dogmas durante toda la época [propiamente] colonial"' (Gruzinski 67; Blanco 89).

En efecto, tal vez el éxito mismo de la empresa misionera de educación de las élites indígenas ayudó a condenar el proyecto representado por el Colegio. Así, el primer concilio mexicano de 1555 "no sólo ordena incautar todos los sermones en posesión de los indios, sino que insta a cuidar muy de cerca los textos que se les entreguen en el futuro, "para que no puedan ni falsearlos ni corromperlos" ". Lo propio recomienda el segundo Concilio de 1565 (Gruzinski 63). Gruzinski apunta cómo estas medidas aluden por igual al grado de difusión de la lectura entre la élite indígena y a una cierta capacidad de reproducción de materiales escritos que escapaban al control eclesiástico (63). De este modo, la Iglesia contrarreformista decidirá, de un modo paralelo al espíritu que anima su control sobre el texto y la lectura de la Biblia, terminar con el proyecto utópico de los misioneros y de allí sin más impulsar, en este segundo sub-momento colonial, 
la catequización uniforme y limitada de los indígenas en la lengua nahuatl de Iglesia que aquellos mismos primeros intelectuales indios ayudaron a elaborar. Ello implicaba un desplazamiento desde la formación de sujetos lectores relativamente independientes (subjetivación de élite) a un modo universal y homogéneo de consideración de los indígenas en que estos a la vez que veían cerrado el acceso al sacerdocio aparecían en la "condición de eternos neófitos y de menores espirituales" (Gruzinski 74; Gonzalbo 1990, 98 y 1988, 44) en que habría de transcurrir su existencia colonial. En este cambio de política se alteraban pues las relaciones del sujeto con el texto. Estas relaciones aparecían ahora mediadas y estrictamente limitadas por la intervención productora y reguladora de la semiosis que los sacerdotes llevarían a cabo en espacios y discursos claves como los confesionarios y los manuales de enseñanza moral. Sonia Corcuera ha descrito este paso de la Iglesia previa al Concilio de Trento a la postridentina con la frase "del amor al temor". La expresión quiere graficar la transición desde la plena incorporación del indígena al cristianismo, que caracteriza el primer período, al giro pesimista que la catequización toma cuando los sacerdotes se creen obligados a "reducir y simplificar los contenidos de la enseñanza para adaptarlos a la menor capacidad, y a la especial inteligencia de los naturales" (Corcuera 19).

Los primeros esfuerzos de alfabetización controlada de las élites indígenas produjeron, sin embargo, otro resultado histórico duradero. Marcaron la cuasi-desaparición de la oralidad prehispánica de élite ligada a la "lectura" de las pinturas y glifos y el comienzo de una identificación casi total de la oralidad con la cultura indígena de "las masas campesinas y citadinas" (Gruzinski 65). Inauguraron así una conformación cultural que todavía nos es familiar y en la cual lo oral se identifica con el pueblo y lo rural, mientras que la letra se instala en el centro urbano de la élite (Rama, Lienhard). La aparición masiva de sectores sociales medio-bajos en los grandes centros urbanos de la segunda mitad del siglo XIX traería, como veremos, un renacimiento de las relaciones productivas entre oralidad y escritura en la forma de la lectura colectiva, la literatura de cordel y el arte de los payadores.

\section{El momento decimonónico}

\section{Cultura patricia - cultura burguesa}

A la configuración colonizadora ya descrita seguirán el momento colonial propiamente dicho y, luego, los esfuerzos borbónicos por controlar y dirigir el flujo de las ideas de la ilustración europea, seleccionando cuidadosamente las que parecían más compatibles con las realidades autoritarias y católicas de América. A partir de la independencia los estados postcoloniales y los grupos de élite que 
los lideraban, a menudo después de haber usado con contundencia el potencial subversivo de las letras y de la imprenta para promover dicha independencia, intentan reposicionar la literatura (y en general la producción de discursos) al interior de la formación discursiva nacional. Esto se desarrolla poco a poco en un proceso algo contradictorio en que al mismo tiempo en que se limita y dosifica la llegada y el acceso popular a esos discursos, se verifica, por un lado, una explosión de los discursos impresos (que hacen posible y en la cual participan tanto liberales como conservadores) y, por otro, al menos por parte de los liberales, un ataque secularizador a la perspectiva ideológica que empezaba a animar la censura eclesiástica de ese bullente mercado editorial.

Durante el siglo XIX la expansión de la literatura al interior de los espacios domésticos, que alcanzaba así ya no solo a las mujeres de la élite sino también a los sectores medios, obligó a la Iglesia a comprender que una de las formas más poderosas del proceso de secularización con que las ideas liberales amenazaban su supervivencia en las antiguas colonias, era ahora precisamente la proliferación de publicaciones destinadas ya no solo a la élite de hombres públicos sino, cada vez más fuertemente, a sectores crecientemente amplios de la sociedad (Poblete 1999).

Ignacio Manuel Altamirano apuntaba indirectamente en 1871 a la importancia de un cambio ya perceptible en la época:

Ya se ve: las mujeres antes no sabían nada; el ideal del clero era la mujer ignorante, y con razón, para dominarla a su sabor, era preciso que nada supiera. Una mujer que apenas supiera leer su devocionario, era lo más propio para hacer un instrumento ciego. Y todavía en los países atrasados, como España y México, se cree por la gente antigua que la mujer debe ser ignorante. ( $L a$ misión del escritor 226)

Ambrosio Fornet señala, por su parte, cómo en la Cuba del siglo XIX "Antes de que el periódico se convirtiera en un objeto familiar para las clases populares, la propaganda religiosa en sus diversas formas impresas fue el único 'eco' que la imprenta llevó a todos los estratos de la sociedad" (6o).

En aquella expansión, de vastas consecuencias políticas y culturales, la literatura de ficción tendría un papel fundamental. Dentro de este esquema, la lectura literaria o, más ampliamente, la lectura de discursos socialmente circulantes experimenta una serie de transformaciones determinadas a su vez por varios desarrollos históricos nuevos. Paralelamente a una masificación al menos tendencial y evidente para los contemporáneos en la circulación de libros e impresos (Henríquez Ureña 59 y 94; Fornet; Subercaseaux 1993), se produce a lo largo del siglo XIX una separación relativa de la Iglesia y del Estado que como instituciones 
carecen del grado de identificación o complementariedad que había distinguido la época colonial (The Conflict...; Hamnett). El control tanto de dicha producción y circulación como de su misma interpretación resulta, entonces, mucho más complicado e inefectivo en el momento en que las agendas seculares y religiosas comienzan a divergir. Además, no solo aumenta la circulación de libros sino que, y este es cuantitativa y cualitativamente el factor decisivo, la producción y circulación de impresos (sobre todo periódicos y diarios) obliga a una redefinición del objeto del control. Esta proliferación de discursos va acompañada, por supuesto, de una relativa pero importante diversificación de los sectores que tienen acceso directo - no mediado por los sacerdotes - a esas lecturas. Es decir, los sujetos del control también requieren una redefinición. Los indios son ahora reemplazados por las mujeres, primero de las élites y luego de los sectores medios y, hacia el fin del siglo, por los artesanos y pequeños comerciantes de los sectores medio-bajos. En este paso del libro escaso y elitario al periódico y los impresos (relativamente) abundantes y masivos ocurre como si el discurso escrito — que con el libro había subsumido y colonizado tanto su propio origen europeo medieval (en los pliegos, pergaminos y folios) como las formas de escritura no alfabética de los amoxtli de los pueblos indígenas conquistados - se rebelara contra esta compresión de sus orígenes y se redesplegara en la forma abierta, moderna y perecible del periódico.

Domingo Faustino Sarmiento destacaba precisamente la función popularizadora y progresista de la lectura masiva y constante de novelas en los periódicos: En el Paraguay y en Chiloé, todos saben leer; lo único que les falta para no ser los dos pueblos más atrasados entre nosotros es leer. No hay libros ni objetos [o motivaciones] para leerlos, si los hubiera. Con las novelas y los diarios empiezan [esos lectores] a ejercitar aquella adquisición estéril. ("Las novelas" 161)

En el periódico, por último, se produce esa convivencia epocal y propiamente decimonónica de discursos que habían siempre pertenecido a esferas y a sectores nítidamente separados: ensayos, política, ficciones sentimentales e históricas masivas, almanaques, consejos, crónicas policiales, noticias de negocios, etc.

De este modo se entiende la queja del colombiano Miguel A. Caro, uno de los letrados paradigmáticos del siglo XIX latinoamericano. En "Ligera excursión ideológica", que es un trabajo filosófico sobre la "operación mental llamada juicio y sus elementos", Caro comenta:

Dirán algunos, y no sin razón, que este estudio es más propio de un libro o de una revista que de un periódico. Pero entre nosotros ¿quién va a publicar un libro sobre un punto de filosofía especulativa? Las condiciones del país hacen que el periódico reuna los caracteres de tal y de revista y de libro al mismo 
tiempo. Tal lo hemos entendido en la redacción del nuestro. [...] Quedaremos recompensados si la lectura de estos ligeros apuntamientos desengañare del error en que están, a algunos de aquellos jóvenes compatriotas que profesan, sin saber lo que hacen, el principio sensualista, y si ella por otra parte mereciere la atención ilustrada de nuestros suscriptores de fuera de la república, que prefieren en nuestras columnas los artículos serios y originales, a las gacetillas, cuentos y en general a la literatura frívola y ligera, destinada a otra clase de lectores. (Caro, "Ligera excursión ideológica" 225-226)

Caro alude aquí a dos puntos importantes en el contexto de nuestra discusión: el lugar de los periódicos como instrumentos culturales y su público lector. En primer lugar se refiere a las que podríamos llamar condiciones constitutivas de la "publicidad" que encarnaban los periódicos en países que carecían de un aparato productor del libro dotado de un desarrollo suficiente. En tanto periódico, revista especializada y libro, todo simultáneamente, el periódico se proponía a sí mismo como un espacio textual de facto en que diversas comunidades de lectores y lectoras practicaban sus pertenencias diferenciales a una misma formación lectora nacional. En segundo lugar, Caro distingue entre un público ilustrado y "otra clase de lectores". Esta clasificación, esta pertenencia de clase que separa a los lectores, coincide con sus preferencias de lectura: hay un sector serio e ilustrado que lee artículos graves y otro, frívolo, que ocupa su tiempo con gacetillas y cuentos. La literatura ilustrada se opone a la literatura ligera del mismo modo en que serio se opone a frívolo. Ello supone, de una parte, una reiteración de la oposición tradicional entre dos tipos de lectura diferentes: la intensiva y la extensiva, la masculina e ilustrada y la femenina o frívola-ligera; y de otra, la repetición de la jerarquía discursiva que distingue "las gacetillas, cuentos y en general a la literatura frívola y ligera", es decir la prosa novelesca, del género literario por antonomasia para Caro, es decir, la poesía.

En realidad, el mismo título de su artículo, "Ligera excursión ideológica", el nombre del periódico (El Tradicionista) que Caro funda y edita y en el que aquel aparece, $y$, finalmente, el hecho de que para encontrar lectores ilustrados se crea obligado a buscarlos en el extranjero, todo ello evidencia el clima y las presiones comerciales nuevas que Caro enfrentaba en la novedosa configuración propuesta por lo que hoy llamaríamos un mercado editorial. Descubre asimismo que tras esas pertenencias diferenciales a una misma formación lectora nacional se escondía también una forma de comunión cultural, en que al menos en relación a ciertos discursos como la ficción, las "clases de lectores" perdían nitidez, se mezclaban y diluían en la aparición de un público nacional burgués más mesocrático y abarcante que el aristocrático de antaño. 


\section{Lectura intensiva-extensiva y la lectura nacional}

La Iglesia, que durante buena parte del siglo XIX cifró sus posibilidades de permanencia y justificación socio-política en el seno de los estados postcoloniales en el control y adoctrinamiento tanto de la virtud de las mujeres como en la sumisión y acatamiento de los sectores populares, no puede sino haber visto en la masificación de la lectura, y en particular de la lectura de ficción, una suerte de perverso retorno de lo reprimido, el regreso de otros discursos dichos para y con el corazón caliente que tanto trabajo y sangre le había costado, trescientos años antes, intentar extirpar del suelo americano.

Los discursos de la ficción popular eran los mismos que habían ocupado también el fanatismo censurador y paradójico de Jean Jacques Rousseau. Estudiando el caso extraordinario del francés Jean Ranson, lector asiduo y fervoroso de la obra literaria de Rousseau, Robert Darnton ha enfrentado la tarea de historizar la lectura como práctica. Darnton combina la discusión de las 47 cartas conservadas de las lecturas de este buen burgués provinciano, en muchos respectos similar al nuevo público de lo que luego llamaremos la ficción nacional en América Latina, con los escritos de Rousseau, para llegar a conclusiones muy útiles en nuestro contexto.

La paradoja del autor de La Nouvelle Heloise es que él mismo había predicado ampliamente en contra de las novelas. ¿Cómo era posible que ahora escribiese una? "Rousseau's reply in the prefaces is deceptively simple: 'This novel is not a novel"' (Darnton 1985 229). En efecto, Rousseau se proponía con La Nouvelle Heloise la creación de "another cultural form, an anti-literature literature, in which he could defend the cause of virtue by appealing directly to the unsophisticated" (Darnton 231).

Mientras que en Rousseau esta era una reacción a lo que él consideraba la corrupción imperante en los salones literarios franceses que aun en el caso de los filósofos enciclopedistas no hacían, en su opinión, más que reproducir el elitismo y la decadencia moral propias del Ancien Regime, en América Latina surgirían proyectos liberales de una novela nacional que, en lo fundamental, intentarían responder al mismo problema: cómo hacer una literatura que además de entretener a los lectores los educara con el tipo de conocimientos y disciplinas morales que las nuevas repúblicas requerían en la visión de sus adalides liberales.

El novelista Alberto Blest Gana, considerado tradicionalmente el padre de la novela chilena, creyó encontrar la respuesta en su propuesta de una novela de costumbres nacionales. El tema lo desarrolló en 1861 en su famoso discurso de incorporación a la Facultad de Humanidades de la Universidad de Chile, titulado "La literatura chilena: algunas consideraciones sobre ella". Se trataba, 
en lo fundamental, de hacer frente con un producto nacional a la proliferación de novelas-folletines extranjeras en los periódicos de la época.

Lo que estaba en juego se percibe cuando se compara cómo la misma situación editorial que traería en Chile un fuerte desarrollo de la producción literaria nacional, significó en Cuba, bajo las diferentes condiciones socio-políticas y económicas del colonialismo, el fin del proyecto literario liberal cubano de los años de 1830. Ambrosio Fornet señala así la paradoja de que "la narrativa cubana se qued[ara] sin suscriptores ni editores en el preciso momento en que más novelas se publicaban y consumían en Cuba" (Fornet 124). Esa literatura nacional había sido desplazada por los folletines franceses y las novelas románticas extranjeras bajo los imperativos del mercantilismo editorial. Como veremos en el caso chileno, esta "desnacionalización" de la literatura circulante en el ámbito nacional no era, sin embargo, el único resultado posible o necesario de la explosión editorial y de la aparición de un público de nuevo cuño. Además, esta llamada "descubanización" señalaba, incluso en Cuba, la irrupción en el espacio letrado tradicional de un público radicalmente nuevo (las mujeres, aun cuando inicialmente fueran en su mayoría de clase alta) y de una sensibilidad y gusto literario alejados del elitismo letrado.

Más que intentar resumir o comentar in extenso aquel ensayo de Alberto Blest Gana (Poblete 1999), me interesa aquí derivar las consecuencias de su propuesta para una consideración histórica de la lectura.

En la primera escena de su primera novela La fascinación (llamada para mayor redundancia "Una escena social", publicada como folletín en 1853), Blest Gana había escrito:

Todo eso es falso, dije un día, cerrando indignado un tomo de "La Nueva Heloísa". Detesto esas virtudes lacrimosas, tan recatadas en el sensualismo que lloran sobre una falta cometida hasta encontrar de nuevo la ocasión de cometerla. Y lleno de despecho contra el pacífico ciudadano de Ginebra [Rousseau], arrojé el libro hacia la extremidad opuesta de la mesa y apoyé mi frente sobre la mano izquierda, actitud en la cual suelo quedarme largos instantes en meditación. (La fascinación 51)

Lo que me importa destacar en esta cita es su dramatización de lo que yo llamaría las condiciones históricas de la situación de lectura en el Chile de la segunda mitad del siglo XIX.

La cita comienza en un nivel claramente metarreflexivo. Esta es una novela que se abre con un lector que cierra indignado otra novela. La primera es una novela nacional chilena, la segunda una obra famosa de un autor francés. De este 
modo, por un lado, Blest Gana empieza su carrera literaria y su primera novela procediendo a cerrar una novela extranjera, mientras que, por otro, la lectura de la obra nacional empieza cuando la lectura de la europea llega a su término. En esta ecuación una cosa hace posible la otra. La apertura requiere un cierre, el comienzo un final. La pregunta, entonces, se nos impone: ¿dónde comienza la una y acaba la otra? Como ocurre con frecuencia, el límite pareciera unirlas precisamente en el momento en que se las separa. Porque inmediatamente después, el lector-personaje nacional se queda pensativo en un gesto perfectamente estereotipado de la literatura sentimental europea que el mismo Rousseau había impulsado y que el lector chileno que empezaba la obra de Blest Gana reconocería de inmediato en su filiación romántica.

En esta dramatización, entonces, el lector de "Una escena social" reproduce, en otro nivel, la paradoja del lector-personaje que se indigna ante "esas virtudes lacrimosas, tan recatadas en el sensualismo que lloran sobre una falta cometida hasta encontrar de nuevo la ocasión de cometerla". El lector decimonónico de la obra del chileno se enfrenta de inmediato con su propia ambigüedad moral como lector de una novela. De hecho, se podría decir que la frase describe perfectamente el mecanismo seductor e irreprensible que los contemporáneos de Blest Gana, desde diversas trincheras ideológicas, identificaron como característico de la ficción novelesca. Empezar a leer es aquí de manera paradójica ingresar simultáneamente al espacio de la liberación de pulsiones libidinales y al de su censura y control. Apertura y cierre se dan allí la mano.

En el gesto hierático y altamente estilizado de este primer lector nacional se encerraba, además, el dilema al que la novela nacional chilena, al menos en la propuesta de Blest Gana, intentaría responder. En este momento congelado en donde el modelo romántico europeo era usado para, en el mismo gesto, ser descartado como impertinente, asistimos pues al nacimiento oficial de una literatura cuya originalidad y autonomía se fundan precisamente en la creativa dependencia y en la dependencia creativa respecto a modelos foráneos. Más que una relación parasitaria, la escena reproduce a la perfección sus condiciones históricas de emergencia.

Blest Gana, como Rousseau antes que él, se proponía de este modo desarrollar una novela que llamó "de costumbres nacionales" en la cual el lector nacional pudiese relacionar su propia vida como ciudadano chileno con el texto que leía, de una manera que resultara socialmente productiva y personalmente entretenida y transformadora. Es decir, hacer de la experiencia subjetiva de la lectura de ficción un acto de construcción de la nación. Esta transformación en la práctica de lectura, que intentaba combinar los antiguos ideales de edificación moral a través 
de la palabra escrita con las nuevas y modernas demandas del mundo editorial guiado fundamentalmente por la estimulación del consumo, se entiende mejor en el contexto de una de las pocas macrohipótesis de periodización existentes en los estudios históricos de la lectura.

Rolf Engelsing ha propuesto considerar, en la historia de la lectura europea, el paso de una forma de lectura intensiva a otra extensiva. Por intensiva entiende la lectura reiterada de muy pocos textos religiosos que se leían con gran cuidado, detención y respeto. El modelo, para Engelsing, es la lectura protestante de la Biblia, pero también podría serlo en la América Latina de la primera mitad del XIX el uso de los catecismos y libros de oración que habían sido de hecho los primeros best sellers nacionales. Este tipo de lectura habría predominado en Europa desde la Edad Media hasta fines del siglo XVIII. En ese momento, de acuerdo a Engelsing, se habría producido un cambio en el número de libros y escritos disponibles y, como consecuencia de ello, una transformación de los hábitos y formas de lectura. La lectura extensiva es, en efecto, más rápida y se hace sobre muchos y diferentes textos circulantes en el mercado editorial en desarrollo (Engelsing; Chartier 1994; Darnton 1990). Domingo Faustino Sarmiento, por su parte, había ya entendido este lugar de la Biblia en la cultura protestante y se preguntaba cuál era el libro que podría haber ocupado un lugar similar en la cultura católica. Su respuesta compara la práctica intensiva y constante que caracteriza la lectura de la Biblia en los países protestantes con la lectura extensiva de las novelas:

Para ser católico es necesario ante todo tener fé. El catolicismo lo dice. Para ser protestante es preciso saber leer para leer la Biblia [... ¿ ¿Cuál es el libro del católico? [...] ¡Nombradlo! [...] un libro enciclopedia, [...] un libro que sea cuento que interese, fantasía que exalte el espíritu, enigma que aguze la inteligencia, poesía que remonte la imaginación [...] Mostradme ese libro. - No existe. La Biblia existe así. ("Las novelas" 159-160)

En este texto de 1856, Sarmiento alude a la función educacional y de progreso que cumplían o podían cumplir igualmente tanto la lectura intensiva de la Biblia como la lectura extensiva de novelas y folletines. Se refería así a sus planes por capitalizar el interés potencial de los lectores populares en la literatura de ficción en beneficio de la expansión masiva de la alfabetización. Como se sabe, esta expansión elemental de la cultura era para el argentino una de las precondiciones que habían hecho posible el extraordinario desarrollo de la industria y el comercio en la república modélica de los Estados Unidos:

[...] el medio más poderoso para levantar el nivel intelectual de una nación, diseminando la educación en todas las clases sociales, es fomentar el hábito 
de la lectura hasta convertirlo en un rasgo distintivo del carácter o de las costumbres, como sucede en la Alemania y en los Estados Unidos. (Sarmiento "Bibliotecas populares" 396)

En 1876, el chileno Alfredo Ovalle, por otro lado - respondiendo ya, en general, al desarrollo efectivo de la industria editorial y, en particular, a la abundancia de periódicos (y con ellos de lecturas de ficción folletinesca) - proponía en un artículo sobre "Los libros y los lectores" un regreso a las formas intensivas de la lectura de uno o dos libros esenciales y el abandono de la superficial lectura extensiva:

La creencia tan común de que para considerarse hombre instruido una persona le basta con haber leído, de cualquier modo que sea, muchos libros es tan equivocada como la de cierta escuela política [...] Por eso es tan cierto el proverbio Timeo homo unius libri. En efecto: ¿quién sería más sabio que aquel que verdaderamente poseyera la Sagrada Biblia ni quien mejor lengüista que aquel que más hubiera conversado con Cervantes? (Ovalle 264)

Por su lado, armado de lo que en otra parte he llamado "su poderoso liberalismo transaccional" (Poblete 1999), Blest Gana le propuso a su público nacional que, en vez de aceptar el consumismo barato y fácil que la industria masiva editorial y literaria francesa le ofrecía, se decidiese a leer un nuevo tipo de texto nacional que, dotado de una densidad no prohibitiva ni discriminadora, por estar basada en formas comunes de vida y en realidades por todos apreciadas, le permitiría y le demandaría una lectura más cuidadosa pero, a la vez, más provechosa y finalmente más entretenida. Le proponía, en suma, un retorno transformado a la lectura semi-intensiva, ahora nacionalizada: "A menos de ser un libro cuya comprensión demande conocimientos previos y especiales, las producciónes de amena literatura encuentran en nuestros círculos ilustrados una acogida benévola y cordial" (1859 51, énfasis añadido).

La novela nacional realizaba así en la práctica el ideal de la nueva lectura antiliteraria de literatura que Rousseau les había ofrecido a sus lectores. En ella la vida diaria y el corazón del ciudadano/a se abrían directamente y (supuestamente) sin mediación de discursos letrados tradicionales al impacto de una palabra que quería ser tan seductora como verdadera y edificante. Por ello, en la concepción de Blest Gana, esa novela nacional se cuidaría muy bien de no exigir nada más que lo que todo chileno de la sociedad respetable ya poseía por el mero hecho de pertenecer a ella. La poesía, en cambio, requería de una preparación especial que la ponía fuera del alcance de muchos de esos mismos ciudadanos y ciudadanas: 
La novela, con efecto, cuenta entre la generalidad de los lectores, con un número mucho mayor de aficionados que la poesía, porque la primera está al alcance de todos, mientras que para gustar de la segunda, se ha menester de un espíritu más connaturalizado con los preceptos del arte [...] Mientras que la poesía conserva siempre para el vulgo la apariencia de los antiguos ídolos cuyo lenguaje era comprensible únicamente a los sacerdotes del culto pagano, la novela, por el contrario, tiene un especial encanto para toda clase de inteligencias, habla el lenguaje de todos, pinta cuadros que cada cual puede a su manera comprender y aplicar y lleva la civilización hasta las clases menos cultas de la sociedad, por el atractivo de escenas de la vida ordinaria contadas con un lenguaje fácil y sencillo. (Blest Gana 1977 119)

Digamos de paso que, en nuestro contexto, resulta notable que Blest Gana haga referencia directa al control eclesiástico (aunque pagano) de los discursos sociales y al contraste entre ese esoterismo y la novela que él propiciaba.

En un artículo crítico aparecido en 1864 para comentar la publicación de otra novela de Blest Gana, El ideal de un calavera, Benjamín Vicuña Mackenna decía, resumiendo la percepción letrada tradicional a la sazón todavía influyente:

La novela se considera, pues, entre nosotros como una impertinencia, como un peligro, casi como un acto de mala educación, y en consecuencia los novelistas pasan por seres raros, mitad pecadores y mitad calaveras, que es preciso mirar con desconfianza, y cuyos libros no pueden leerse sino a hurtadillas, metiéndolos con astuto cuidado dentro de los sendos volúmenes del Año cristiano para que no se enfade la mamá, ni murmure el capellán o la llavera. (239)

La cita aclara varios puntos en nuestra discusión. Para empezar se comprende entonces que Blest Gana hubiese comenzado su primera novela con esa escena en que censura, placer y lectura se imbricaban aludiendo simultáneamente a los peligros y posibilidades que la cultura de la época asignaba al género novelesco. Luego, se percibe hasta qué punto la novela de costumbres nacionales en Blest Gana responde y representa directamente una de las costumbres chilenas que más preocupaban a la Iglesia de la época: la intromisión de la lectura individual y privada de ficciones en el espacio antes cuasi exclusivo de las lecturas piadosas. El híbrido de Blest Gana, mezcla de novela y de edificación, procedía entonces "con astuto cuidado" a hacer posible la legitimación de un tipo de lectura que antes solo se hacía "a hurtadillas". Ponía pues, en contacto, las funciones que la Iglesia y el Estado le habían asignado históricamente a los discursos escritos y a sus lecturas con un nuevo género literario y de lectores. 
Esta solución, claro está, no resultaba satisfactoria para todos. En el otro extremo del espectro ideológico, Miguel Antonio Caro, por ejemplo, revelaba, discutiendo la obra de Jorge Isaacs, hasta qué punto la novela en tanto práctica cultural exigía una respuesta ideológica del bando conservador. En la jerarquía cultural de Caro, la poesía, como forma de discurso divinamente inspirado, ocupaba el lugar más alto. Por ello al comentar la obra de Isaacs señalaba: "El señor Isaacs es conocido en Colombia y en otras regiones hispanoamericanas como novelista y poeta, mejor dicho como poeta exclusivamente, porque María no es una novela, (y si tal se juzgase, sería una mala novela), es un idilio, un sueño de amor" (Caro, "El Darwinismo y las misiones" 1050-1051).

Y lamentando que la obra poética de Isaacs no le hubiese reportado beneficios pecuniarios a su autor, Caro aclaraba:

[...] el señor Isaacs, después de publicar la María y sus Poesías, escritas cuando era espiritualista y creyente, no ha vuelto, en veinte años, a escribir ningún libro ni cosa alguna de mérito literario. Parece que el materialismo le ha esterilizado [...Y continuaba:] Hay pecados contra el Espíritu Santo, y en otro orden de ideas hay pecados contra la poesía que no se perdonan jamás [...] Esto es lo que deploramos y esto lo que no le han perdonado las musas, porque poeta materialista es una antinomia, un imposible. (1050-1051)

Esta defensa de la poesía y ataque de la novela y del materialismo contemporáneos eran para Caro el resultado de una propuesta cultural que intentaba retornar la educación y la literatura colombianas al marco del humanismo clásico. (Poblete "Literary Education") En este modelo, la poesía grecolatina reinterpretada en una vena cristiana y católica ocupaba el lugar más alto en la jerarquía cultural y cumplía abiertamente funciones de distinción social fundadas en el capital cultural acumulado:

[...] los estudios literarios al mismo tiempo que aguzan la inteligencia la pulen y abrillantan [...] El célebre Macaulay asienta [...] que los estudios clásicos marcan la línea divisoria entre el caballero y el salvaje. ${ }_{\mathrm{c}} \mathrm{Y}$ podremos sin grave perjuicio para la civilización, prescindir de ese ramo de la educación pública, de este saludable correctivo en las democracias, tan ocasionadas como son a la grosería y al desorden? (Caro, "Oración de estudios pronunciada en el acto de la solemne distribución de premios del Colegio del Espíritu Santo el día 15 de noviembre de $1880 " 1382$ ).

La defensa de lo escaso y lo selecto entrañaba una recuperación de la lectura intensiva tradicional y, como vimos más arriba, una correctora resistencia, en general, 
a las presiones culturales y políticas igualitarias que, para Caro, caracterizaban las democracias modernas y, en particular, una resistencia a la lectura extensiva propia de "la literatura frívola y ligera, destinada a otra clase de lectores". La lectura de estudio, reconcentrada e intensa, el desciframiento cuidadoso de los textos clásicos, eran, para él, las formas apropiadas para la única lectura que merecía el nombre de tal.

Intentando nuevamente oponer la lectura de novelas a la lectura católica de libros religiosos, Sarmiento describía, en cambio, la cultura letrada tradicional del patriota y jurista argentino Dalmacio Vélez Sarsfield (1800-1875) del modo siguiente:

Murió sin haber leído una sola novela en toda su vida; y se lamentaba a veces de no entender el libreto de las operas, por no estar en antecedentes del drama que había servido de tema [es decir, por no poder filiarlo a un texto modélico, un procedimiento típico de la cultura letrada tradicional]. Esta que parece una originalidad en quien tanto tenía el poema épico de Virgilio, que parecería abrir el ánimo a los goces de la imaginación, era sin embargo efecto de un defecto de la antigua educación monástica de nuestras Universidades. El sentimiento de lo bello no sólo no era cultivado por ningún estudio, sino que quedaba atrofiado el que nos viene de la naturaleza. Las bellas artes, las formas, la imaginación no tuvieron un altar en aquellos claustros de murallas lisas y sombrías en que se murmuraba latín, o se repetían autores de derecho o de teología. ("Vélez Sarfield" 312)

Para graficar los efectos de este tipo de lecturas sobre aquellos que carecían del entrenamiento humanista tradicional, Sarmiento mencionaba el siguiente ejemplo:

Dadle a una niña de quince años un libro de los que llamais serios. No lo leerá, porque no puede concentrar su movible atención, porque su inteligencia carece de nociones, y sus ojos no están habituados a recorrer, sin fatiga y con rapidez, ese enteclado de letras, de signos y de notas que contiene un libro; y sus ojos se rinden y el sueño los cierra. ("Las novelas" 160)

Las novelas editadas por los periódicos, y puestas así al alcance de un público nuevo y tendencialmente masivo, abrían en cambio la puerta a la ejercitación de esa capacidad embotada de lectura. Como práctica de la vida diaria, la lectura de novelas desarrollaba tanto la inteligencia como la sensibilidad y, de este modo, generalizaba la "civilización" entre aquellos que "sin su aguijón no habrían jamás tomado un libro en las manos" ("Las novelas" 160). Concurrente era la opinión de Ignacio M. Altamirano en México: 
Las novelas de [Juan] Mateos, cualesquiera que sean los defectos que les eche en cara la crítica, tienen el mérito de popularizar los acontecimientos de nuestra historia nacional, que de otro modo permanecerían desconocidos a los ojos de la multitud, supuesto que los anales puramente históricos no son fáciles de adquirir por los pobres, ni agrada su lectura por carecer del encanto que la narración novelesca sabe darles. (1969 265)

Combinando de hecho en 1868 las posiciones de Sarmiento y Blest Gana, Altamirano daba así voz en México a la defensa de la novela nacional como instrumento esencial en la construcción de la nación. Marcando la distancia entre la concepción tradicional y la nacionalista respecto a la novela, Altamirano agregaba:

No hay que decir ahora que la novela es una composición inútil y frívola, de mero pasatiempo, y de cuya lectura no se saca provecho alguno, sino por el contrario, corrupción y extravíos [...] generalmente hablando, la novela ocupa ya un lugar respetable en la literatura, y se siente su influencia en el progreso intelectual y moral de los pueblos modernos... (1991 70)

Altamirano aludía, además, a una transformación epocal decisiva en la transición desde las sociedades patricias a las sociedades burguesas nacionales en América Latina (Romero). Me refiero al paso de las pedagogías centradas en los clásicos grecolatinos cuyos modelos se memorizaban a través de repetidas lecturas hacia aquellas en que primaban las formas de identificación inmediata de los ciudadanos con sus contextos cotidianos nacionales (Poblete 1997): "Todo lo útil que nuestros antepasados no podían hacer comprender o estudiar al pueblo bajo formas establecidas desde la Antigüedad, lo pueden hoy los modernos bajo la forma agradable y atractiva de la novela..." (Altamirano, 1991 70).

Este cambio metodológico, sin embargo, no se haría totalmente efectivo hasta las reformas positivistas de la educación que cerrarían el siglo XIX. Prueba de ello es que Altamirano se creyó obligado a agregar estos comentarios tranquilizadores que reestablecían las jerarquías y las diferencias tradicionales en las diversas formas de acumulación de un capital cultural:

No concluiremos este ensayo, sin advertir que nosotros hemos considerado la novela como lectura del pueblo, y hemos juzgado su importancia no por comparación con los otros géneros literarios, sino por la influencia que ha tenido y tendrá todavía en la educación de las masas. La novela es el libro de las masas. Los demás estudios, desnudos del atavío de la imaginación, y mejores por eso, sin disputa, están reservados a un círculo más inteligente y 
más dichoso, porque no tiene necesidad de fábulas y de poesía para sacar de ellos el provecho que desea. (Altamirano, 1991 76)

Repetía así el gesto entre conciliador y conservador de Alberto Blest Gana en Chile. En formaciones discursivas y lectoras aún en proceso de transición, desde las formas de literacy y capital cultural dominadas por la poesía y los clásicos, hacia otras en que comenzaban a dominar la prosa periodística y novelesca, el reconocimiento de la legitimidad de aquellas y el paternalismo hacia éstas parecían la actitud más segura y natural para los nuevos intelectuales nacionales.

\section{Otras formas de lectura}

La identificación del cambio desde una lectura intensiva de unos pocos textos, a menudo memorizados y verbalizados, hacia una lectura extensiva de múltiples textos con la consiguiente desacralización del objeto y los contenidos leídos, fue uno de los factores que le permitió a Blest Gana formular su propuesta de una lectura nacional semi-intensiva y abierta a las capacidades lectoras de un público mesocrático (o, para decirlo de otra forma, al alcance del capital cultural y los intereses de sectores más amplios de la sociedad nacional). La hipótesis que teoriza dicho cambio de lo intensivo a lo extensivo en la práctica de la lectura ha sido uno de los tres pilares fundamentales en la constitución de los emergentes estudios históricos de la lectura (Chartier, 1995 143). Los otros dos han sido la identificación de la transición en la Europa medieval desde una lectura cuya comprensión requería la vocalización de lo leído a una lectura silente y puramente visual, por un lado; y, por otro, el contraste entre una lectura íntima, cerrada y solitaria y otra lectura colectiva en espacios comunitarios.

Antes de cerrar este ensayo, me gustaría referirme someramente al menos a este último aspecto en el contexto latinoamericano. La llegada de la lectura silente y solitaria de la novela nacional no debe pues ocultarnos la existencia anterior y posterior de otras formas de lectura en el continente. Hemos mencionado ya la presencia de una forma de oralidad de élite y de una desarrollada retórica en los pueblos prehispánicos de México (León Portilla 1989). A ella deben agregarse, por ejemplo, los textos que conforman los cantos-poesía preservados en el códice Cantares mexicanos. De ellos me interesa destacar aquí la naturaleza de su codificación y performance. Como productos, en su gran mayoría, de la situación colonial del tercer cuarto del siglo XVI, los Cantares codificaban en un lenguaje altamente formalizado las invocaciones de la antigua historia y sabiduría. John Bierhorst enfatiza el punto citando las quejas de los misioneros españoles ante el esoterismo impenetrable de los cantares. Más allá de las complicadas 
estructuras semánticas y sintácticas de los cantos y del arte de los cantantes-poetas encargados de interpretarlos, los Cantares son un ejemplo de la imbricación de poesía-música-danza-religión que parece haber caracterizado muchas manifestaciones culturales prehispánicas. Bierhorst apunta: "There is no reliable evidence that Aztec 'poetry' was ever recited apart from music or ever committed to writing for the enjoyment of the silent reader" (42). Miguel León Portilla, por su parte, destaca la relación simbiótica que existía entre la oralidad y la escritura en la "lectura" de los códices prehispánicos nahuas y mixtecas aprendida en las escuelas por los aspirantes a sabios y sacerdotes. Las palabras amoxohtoca y tlapoa, "seguir el camino del libro" y "contar', "recitar" lo que estaba inscrito en él" respectivamente, dan cuenta de esa imbricación compleja o complementariedad de memorización basada en la oralidad formal y saber decodificador fundado en el conocimiento del lenguaje pictoglífico (León Portilla, 1996 19-71). De cualquier modo, las lecturas-performances de los antiguos mexicanos nos recuerdan la historicidad de nuestras propias formas adquiridas de desciframiento e interpretación textual. Es decir, nos señalan simultáneamente la existencia de otras maneras de "lectura" y el carácter productive que esta tiene en relación al texto. Apuntan también a una conexión diferente entre el cuerpo del "lector" y el texto. Así, cabe destacar la importancia del cuerpo del lector-intérprete en el mundo nahuatl y en su conceptualización de los procesos socio-semióticos (Mignolo, 1995 109-118). Tanto para los ancianos, que en sus propios cuerpos eran los depositarios de un saber oralmente transmitido, como para los jóvenes, que debían dominar el arte retórico de la performance, las conexiones entre cuerpo y discurso eran diferentes a las europeas en que empezaba a dominar la neutralización del cuerpo en la lectura silente y solitaria.

Desde ese momento, pasando por la excesividad de las fiestas y ceremoniales barrocos hasta llegar tres siglos más tarde al XIX, estas formas de lectura y performance colectivas habrían de representar siempre desafíos potenciales a la dominación de los letrados, el libro y los privilegios escriturarios en el continente. En algunas tabaquerías cubanas, por ejemplo, surgió hacia fines de 1865 la costumbre de pagarle a un Lector para que leyese en voz alta para el entretenimiento y la educación de los demás obreros que trabajaban. El sueldo del lector, que era también un operario, era recolectado de las contribuciones de cada uno de los oyentes. Bajo las condiciones socio-políticas del colonialismo español, sin embargo, la iniciativa fue percibida como una amenaza intolerable y prontamente suprimida. El bando que las prohibía señalaba:

Con la tolerancia de las lecturas públicas vienen a convertirse en círculos políticos las reuniones de los artesanos, y esta clase de la sociedad sencilla y laboriosa, 
que carece de instrucción preparatoria para poder distinguir y apreciar las falsas teorías de lo que es útil, lícito y justo, se deslumbra y alucina fácilmente con la exagerada interpretación de las doctrinas que escucha. (Fornet 189)

En lugar de estas lecturas colectivas en donde el control semiótico de la clase dirigente se veía relajado al mismo tiempo que las capacidades de procesamiento semántico de los obreros se potenciaban en su colectividad, el bando oficial proponía la lectura, en el contexto escolar tradicional, de textos "aprobados por las autoridades competentes" en donde la significación se encontraba debidamente limitada:

La lectura de la doctrina cristiana, de los bandos de buen gobierno y disposiciones de las autoridades, las lecciones que enseñan la manera de conducirse con moderación y urbanidad, y los tratados escritos sobre las artes y oficios, son los libros que educan y enseñan a las clases menos privilegiadas, formando honrados padres de familia y ciudadanos laboriosos o útiles a la patria. (189)

La subversividad potencial de las lecturas había sido, de hecho, justamente apreciada por aquellas "autoridades". Desde 1884 hasta 1896 en que fueron nuevamente proscritas, las lecturas colectivas en las tabaquerías cubanas reaparecieron ahora dominadas por los textos anarquistas de José Llunás, Proudhon y Bakunin. Junto a ellas surgieron las lecturas colectivas en las tabaquerías de la emigración cubana perseguida por el gobierno colonial, en donde al decir de Fornet contribuyeron a "difundir la ideología mambisa y a crear en los talleres verdaderos focos de cultura nacional-revolucionaria" (191).

Otro fenómeno característico, aunque no exclusivo, de la segunda mitad del siglo XIX es el desarrollo de las formas escritas de circulación de las literaturas populares. Su estudio es posible hoy gracias, entre otras fuentes, a la labor de filólogos alemanes como Rudolf Lenz y Roberto Lehman-Nitsche (Subercaseaux 1988; Prieto). En busca de las formas populares específicas y características de formaciones culturales precapitalistas, estos herederos decimonónicos del fervoroso trabajo de recopilación de misioneros coloniales, como fray Bernardino de Sahagún, recolectaron hacia fines del siglo XIX importantes colecciones de impresos populares de circulación y consumo masivos. En ellas se repetía, ahora con algunas variantes importantes, el complejo proceso de escritura, producción y preservación de los legados indígenas prehispánicos y coloniales. En estas formas escritas de lo oral, entonces, se contactaban tradiciones y formas de pensamiento y circulación cultural diversas. Entre aquellas diferencias deben destacarse el origen popular de la mayoría de los productores y consumidores y 
el carácter efectivamente masivo de estas hojas sueltas, folletos, cancioneros para "cantar con guitarra", novelas y folletines. Como en la lectura de las tabaquerías, en este circuito cultural coexistían y se completementaban formas diferentes de apropiación y consumo de los textos impresos. Por un lado, el trabajo de extensión de la alfabetización promovido y aprovechado por Sarmiento, Blest Gana, Altamirano y los demás "constructores de nación", empezaba a dar sus frutos masivos. Surgía así un creciente sector de lectores urbanos populares que reclamaban y hacían posible la producción de una literatura alternativa. Aunque a menudo leída en soledad y en silencio por un lector individual, dicha literatura representaba la fusión de múltiples y heterogéneas tradiciones discursivas, entre las cuales la letrada de élite era solo un componente.

Por otro lado, estas colecciones permiten, entre otros testimonios, apreciar la existencia y extensión del circuito de la lectura y la performance colectiva de discursos populares. En ellas se multiplicaban masivamente en los espacios rurales y urbanos los efectos de la impresión y edición de las hojas sueltas y cancioneros con décimas, versos a lo divino y a lo humano, cantos de contrapunto o payadas, milongas y vidalitas. (Subercaseaux 1988; Prieto). A partir de estos tipos discursivos surgió lo que Guillermo Sunkel denomina "periodismo poético" (en que los sucesos del día son narrados en verso) y "periodismo sin lectores" (pues es 'leído' por un recitador para un público a menudo analfabeto). Sobre él se asentaría luego, en el siglo XX, un periodismo masivo e industrializado de carácter sensacionalista que aprovecharía muchos de aquellos temas, lenguajes y estéticas populares (Sunkel 80).

Finalmente, cabe mencionar en este contexto la llamada literatura de cordel (por la soga en la cual se colgaban para su venta) propia del Nordeste brasileño. Con raíces históricas a menudo similares a las de los cantos y payadas argentinos y chilenos arriba mencionados, los folhetos nordestinos gozan aún hoy de una circulación masiva hecha posible por un fuerte mercado editorial. Estos folhetos, escritos en verso siguiendo la estructura rítmica de la sextilha (estrofa de seis versos heptasilábicos), representan una amalgama popular de las posibilidades combinadas de la impresión escrita y la performance y transmisión oral. Promocionada a través de una lectura pública y a veces cantada en las ferias rurales, la literatura de cordel ha gozado de un público "lector" que privilegia y disfruta las formas orales que la caracterizan:

Although a rise in the national literacy rate means that more people can now read folhetos, many still prefer the oral experience [...] a sizable percentage continues to read the story aloud even when they are alone. Many persons can memorize parts or even whole folhetos after reading them or even after hearing 
them. Individuals who prefer a group reading situation also tend to prefer a live poet to recordings of cordel tales. (Slater 34)

De este modo, la literatura de cordel, como las otras formas de lectura colectiva aquí mencionadas, testimonia la existencia histórica de formas de lectura e interpretación que relativizan la "naturalidad" aparentemente ahistórica de nuestra lectura visual, silente, solitaria e inmóvil.

\section{Conclusión}

Para destacar si no el auge al menos la intensa preocupación educativa traída al continente por la Independencia y el proceso poscolonial del siglo XIX, Pedro Henríquez Ureña señaló en su Historia de la cultura en la América hispánica: "En lugares diversos se dispone [en ese entonces] que los conventos enseñen al pueblo a leer y a escribir: así lo habían hecho en el siglo XVI, pero después olvidaron la costumbre" (59).

Aunque esto es claramente una exageración retórica, sirve aquí para enfatizar la justificación última del privilegio acordado en este trabajo a (solo) dos momentos en el largo devenir histórico americano. Además de las razones prácticas ya mencionadas al comenzar, se trata en ambos casos de momentos en que la lectura y la escritura aparecen con más fuerza como tecnologías importantes en la formación de sujetos súbditos, fieles o ciudadanos. En ellos, dos instituciones claves, el Estado y la Iglesia, reconocen la necesidad de regular la circulación y producción de discursos y las formas de su despliegue o interpretación. Este esfuerzo, como vimos, implicó el control de la semiosis social y de algunas de las formas productivas a través de las cuales esta se realiza, es decir, el control de textos y lecturas. En el siglo XIX, un tercer elemento, el mercado editorial, venía a complicar aquellos esfuerzos reguladores poniendo al alcance de variados y cada vez más amplios sujetos sociales un acceso y una relación más directa entre lector y texto. En el caso del mercado editorial popular y de las lecturas alternativas que este propició, Martín-Barbero ha visto el elemento "que hizo posible a las clases populares el tránsito de lo oral a lo escrito [y] la transformación de lo folklórico en popular" (1987 111).

El proceso entero, claro está, solo era posible en la medida en que las tasas de escolarización y alfabetización fueron en continuo aumento a lo largo del siglo XIX. Carlos Newland ha calculado que para el total de Hispanoamérica (las cifras son mayores para las grandes ciudades y para algunos países como Argentina y Chile) los datos de alfabetización (lectura y escritura) son los siguientes: "menos del $10 \%$ en 1800 [...] $15 \%$ en 1850 y $27 \%$ en $1900 "$ (361). La confluencia en la segunda 
mitad del XIX entre un desarrollo educacional (relativamente) extendido y un mercado editorial finalmente en desarrollo estimuló nuevas formas de apropiación cultural y las consiguientes transformaciones en las jerarquías simbólicas que habían caracterizado las formaciones discursivas y lectoras hasta mediados del siglo. A la sazón, dos modelos generativos de cultura comienzan a trenzarse en larga controversia, que en muchos lugares solo acabaría con las reformas positivistas de la educación hacia el fin del siglo, mientras que en otros se prolongaría hasta bien entrado el siglo XX. Me refiero a dos macro-mecanismos culturales en que la lectura y la relación del sujeto con el texto juegan un papel crucial: de un lado, la imitación de los paradigmas clásicos que es la internalización y reproducción de un modelo superior y jerárquico atemporal en un lenguaje cuidado y selecto (propio de una formación cultural altamente estratificada); y, de otro, la subjetivación pseudoindividualizante y expresiva que, a través de formas y estilos menos exclusivos, busca en el lector y en el educando la respuesta personal y localizada en un tiempo y espacios nacionalizados (propia de formaciones culturales democráticas y nacionales). El primer mecanismo caracteriza al intento evangelizador de la Iglesia y va desde la relación autoritaria y jerárquica, mediada por la formalización del lenguaje eclesiástico, entre los fieles y el texto sagrado hasta la veneración cuasi-religiosa de la cultura humanística greco-latina por parte de los conservadores católicos del siglo XIX. El otro mecanismo es propio del intento educativo laico de los estados nacionales interesados en la formación de sujetos ciudadanos debidamente arraigados en y a su espacio cultural local. A esta última demanda respondían, entre otros, las llamadas de Sarmiento a la alfabetización masiva y los programas de novelas nacionales de Alberto Blest Gana e Ignacio Manuel Altamirano.

En ambos macro-mecanismos de producción cultural, la Iglesia, el Estado y los sujetos individuales intentan determinar los mecanismos legítimos de despliegue de los textos. Estas tecnologías de lectura buscan así, en un tiempo y en un espacio determinados, controlar la semiosis potencialmente ilimitada pero históricamente restringida de los textos.

Aludiendo a las posibilidades y los límites del nuevo énfasis en los lectores y receptores dentro de los estudios comunicacionales y culturales, Jesús MartínBarbero ha señalado que si bien por un lado: "La rehabilitación del sujeto en la recepción ha puesto en primer plano la existencia en nuestra sociedad de matrices y formas culturales distintas de la hegemónica, distintas de la ilustrada y ascética cultura del libro, como lo son las culturas populares" (Martín-Barbero 1987 9-10) abriendo así un vasto campo hacia la democratización posible de lo cultural en América Latina; no es menos cierto que, por otro lado, "el cuestionamiento de la 
idea del emisor omnipotente no puede confundirse ni hacerle juego a la ideología neoliberal que mentirosamente atribuye ‘ ¡todo el poder al consumidor!' negándole a la sociedad y al Estado la mas mínima posibilidad de intervenir políticamente en la regulación de la producción" (9). De manera similar, Nestor García Canclini, en uno de los libros claves en la reformulación teórica que Armand y Michelle Mattelart llaman "el retorno del sujeto" (Mattelart, Armand y Michelle Mattelart 1988 92), advierte sobre la posibilidad de confundir la "descentralización comunicacional" (la multiplicación de la oferta de bienes simbólicos que consideran y apelan a públicos diversos) con una total "desregulación comunicacional", en que a la vez que el Estado se retira o es retirado de la esfera pública cultural, las corporaciones trasnacionales y monopólicas segmentan desigualmente tanto la oferta como el acceso a los consumos simbólicos (García Canclini, 1995 347). De este modo, el estudio de las mediaciones no puede significar el olvido del análisis de la propiedad, estructura y orientaciones de los medios o, para decirlo con los Mattelart: "Un paradigma [como el del retorno del sujeto] rico en potencialidades para rediseñar lo social, [no puede servir] entonces para legitimar un proyecto tecnocrático" (Mattelart, Armand y Michelle Mattelart 1997 109).

Intentando evitar estas Escila y Caribdis de los estudios culturales, es decir, los énfasis alternativos en las estructuras e instituciones versus el que se da a los sujetos, se ha propuesto aquí una consideración histórico-teórica del lugar de la lectura y los lectores en dos momentos de la historia de la literatura latinoamericana. Para ello pareció importante establecer las relaciones entre los macroagentes que intentan determinar los espacios socialmente legibles (Iglesia, Estado y mercado) y los microagentes o sujetos receptores que realizan prácticas lectoras históricamente específicas en esos espacios sociales escritos que llamamos textos.

\section{Obras citadas}

Adorno, Rolena. "Cultures in contact: Mesoamerica, the Andes and the European written tradition". The Cambridge History of Latin American Literature. Volume I: Discovery to Modernism. Eds. Roberto González Echevarría y Enrique Pupo Walker. Cambridge: Cambridge University Press, 1996. 33-57. Impreso. Introduction. Books of the Brave. Por Irving A. Leonard. Berkeley: University of California Press, 1992. ix-xl. Impreso.

Altamirano, Ignacio Manuel. Crónicas de La Semana: de "El Renacimiento" / 1869.

México: Instituto Nacional de Bellas Artes, 1969.

"La literatura nacional". Los novelistas como críticos. Comps. Norma Klahn y

Wilfrido Corral. México: Fondo de Cultura Económica, 1991. 59-76. Impreso. 
Bennett, Tony. Outside Literature. Londres: Routledge, 1990. Impreso.

"Texts in History: The Determinations of Readings and their Texts". Post-

structuralism and the Question of History. Eds. Derek Attridge et al. Cambridge:

Cambridge University Press, 1987. 63-81. Impreso.

Bierhorst,John. Cantares mexicanos: Songs of the Aztecs. Stanford: Stanford University Press, 1985. Impreso.

Blanco, José Joaquín. La literatura en la Nueva España: Conquista y Nuevo Mundo. México: Cal y Arena, 1989. Impreso.

Blest Gana, Alberto. "Literatura chilena: algunas consideraciones sobre ella". Discurso leído por Alberto Blest Gana en su incorporación a la Facultad de Humanidades de la Universidad de Chile, el 3 de enero de 1861. Reproducido en Promis, José. Testimonios y documentos de la literatura chilena. Santiago: Editorial Nascimento, 1977. 108-128. Impreso.

"De los trabajos literarios en Chile". La Semana 11 de junio de 1859. Impreso. La fascinación. Una escena social. La aritmética en el amor. Santiago: Zig-Zag, sin año. Impreso.

Bremer, Thomas. "Historia social de la intertextualidad: funciones de la lectura en las novelas latinoamericanas del siglo XIX (el caso del libro en el libro)". Revista de Crítica Literaria Latinoamericana 24 (1986): 31-49. Impreso.

Caro, Miguel Antonio. "El Darwinismo y las misiones". Obras. Tomo I. Bogotá: 1962. 1049-1107. Impreso.

"Ligera excursión ideológica". Obra Selecta. Caracas: Biblioteca Ayacucho, 1993.224-235. Impreso.

"Oración de estudios pronunciada en el acto de la solemne distribución de premios del Colegio del Espíritu Santo el día 15 de noviembre de 1880". Obras. Tomo I. Bogotá: 1962. 1374-1385. Impreso.

Corcuera, Sonia. Del amor al temor: borrachez, catequesis y control en la Nueva España (1555-1771). México: Fondo de Cultura Económica, 1994. Impreso.

Chartier, Roger. "Labourers and Voyagers: From the Text to the Reader". Readers and Reading. Ed. Andrew Bennett. Nueva York: Longman, 1995. 132-149. Impreso. The Order of Books. Stanford: Stanford University Press, 1994. Impreso.

Darnton, Robert. The Kiss of Lamourette: Reflections in Cultural History. Nueva York: Norton, 1990. Impreso.

"Readers respond to Rousseau: The Fabrication of Romantic Sensitivity". The Great Cat Massacre and other episodes in French cultural history. Nueva York: Vintage Books, 1985. 215-256. Impreso.

De Certeau, Michel. The Practice of Everyday Life. Berkeley: University of California Press, 1984. Impreso. 
Eagleton, Terry. "The Revolt of the Reader". Against the Grain: Essays 1975-1985.

Londres: Verso, 1986. 181-184. Impreso.

Eco, Umberto. Lector in Fabula: la cooperación interpretativa en el texto narrativo.

Trad. Ricardo Pochtar. Barcelona: Lumen, 1981. Impreso.

Engelsing, Rolf. Der Bürger als Leser: Lesergeschichte in Deutschland 1500-1800.

Stuttgart: Metzler, 1974. Impreso.

Fornet, Ambrosio. El Libro en Cuba: siglos XVIII y XIX. La Habana: Editorial Letras Cubanas, 1994. Impreso.

Foucault, Michel. The Archeology of Knowledge. Nueva York: Harper Colophon, 1972. Impreso.

García Canclini, Néstor. Consumidores y ciudadanos: conflictos multiculturales de la globalización. México: Grijalbo, 1995. Impreso.

Culturas híbridas: estrategias para entrar y salir de la modernidad. México:

Grijalbo, 1990. Impreso.

Gonzalbo A., Pilar. Historia de la educación en la época colonial: el mundo indígena. México: El Colegio de México, 1990. Impreso.

"La lectura de evangelización en la Nueva España". Historia de la lectura en

México. México: Colegio de México/Ediciones del Ermitaño, 1988. 9-48. Impreso.

Goodrich, Diana Sorensen. The Reader and the Text: Interpretative Strategies for

Latin American Literatures. Amsterdam-Philadelphia: John Benjamins Publishing

Company, 1986. Impreso.

Gruzinski, Serge. La colonización de lo imaginario: sociedades indígenas y

occidentalización en el México español. Siglos XVI-XVIII. México: Fondo de Cultura Económica, 1991. Impreso.

Hamnett, Brian R. "La Regeneración: 1875-1900". Historia de Iberoamérica. Tomo III:

Historia Contemporánea. Coord. Manuel Lucena Samoral. Madrid: Cátedra, 1987. Impreso.

Henríquez Ureña, Pedro. Historia de la cultura en la América hispánica. México:

Fondo de Cultura Económica, 1961. Impreso.

Horta Nunes, José. Formaçao do Leitor Brasileiro: Imaginario da leitura no Brasil

Colonial. Sao Paulo: Universidade Estadual de Campinas, 1994. Impreso.

La misión del escritor: ensayos mexicanos del siglo XIX. Ed. Jorge Ruedas de la Serna.

México: Universidad Nacional Autónoma de México, 1996. Impreso.

Leal, Ildefonso. Libros y bibliotecas en Venezuela colonial (1633-1767). Tomo I. Caracas:

Academia Nacional de la Historia, 1978. Impreso.

León Portilla, Miguel. El destino de la palabra: de la oralidad y los códices

mesoamericanos a la escritura alfabética. México: Fondo de Cultura Económica,

1996. Impreso. 
_Historia de la literatura mexicana: período prehispánico. México: Editorial Alhambra Mexicana, 1989. Impreso.

Lienhard, Martín. La voz y su huella: escritura y conflicto étnico-cultural en América Latina 1492-1988. Lima: Editorial Horizonte, 1992. Impreso.

López Austin, Alfredo. "La enseñanza escolar entre los mexicas". Ideas, valores y tradiciones: ensayos sobre la historia de la educación en México. Coord. Mílada Bazant. Zinacantepec, México: El Colegio Mexiquense, 1996. 29-40. Impreso.

Martín-Barbero, Jesús. Pre-textos: conversaciones sobre la comunicación y sus contextos. Cali: Ediciones Universidad del Valle, 1995. Impreso. De los medios a las mediaciones: comunicación, cultura y hegemonía. México: Gustavo Gili, 1987. Impreso.

Mattelart, Armand y Michelle Mattelart. "Los Ochenta: retorno del sujeto y mediación tecnológica". Proyectar la comunicación. Comps. Jesús Martín-Barbero y Armando Silva. Bogotá: Tercer Mundo Editores, 1997• 93-119. Impreso. Pensar sobre los medios: comunicación y crítica social. San José, Costa Rica: Editorial DEI, 1988. Impreso.

Mignolo, Walter. The Darker Side of the Renaissance: Literacy, Territoriality and Colonization. Ann Arbor: University of Michigan Press, 1995. Impreso. "Palabras pronunciadas con el corazón caliente': teorías del habla, del discurso y de la escritura". Palavra, Literatura e Cultura. Volumen 1: A Situaçao Colonial. Org. Ana Pizarro. Sao Paulo: Memorial-Editora da Unicamp, 1993. 527-562. Impreso. Morandé, Pedro. Cultura y modernización en América Latina. Madrid: Ediciones Encuentro, 1987. Impreso.

Newland, Carlos. "La educación elemental en Hispanoamérica: desde la Independencia hasta la centralización de los sistemas educativos nacionales". Hispanic American Historical Review 71.2 (1991): 333-364. Impreso.

Osorio Romero, Ignacio. La enseñanza del latín a los indios. México: Universidad Nacional Autónoma de México, 1990. Impreso.

Ovalle, Alfredo. "Los libros i los lectores". La Estrella de Chile. Firmado el 18 de noviembre de 1876. Impreso.

Poblete, Juan. "El castellano: la nueva disciplina y el texto nacional en el fin de siglo chileno". Revista de Crítica Cultural 15 (1997): 22-27.Impreso. "La construcción social de la lectura y la novela nacional: el caso de Alberto Blest Gana en Chile". Latin American Research Review 34 (1999): 75-108. Impreso. "Literary Education and the Making of State Knowledge", Latin American Literary Cultures: A Comparative History of Cultural Formations, Ed. Mario J. Valdés y Djelal Kadir. Oxford: Oxford University Press, Vol. III, 2004. 300-309. Impreso. 
Polan, Dana. "The Public's Fear; or, Media as Monster in Habermas, Negt and Kluge". The Phantom Public Sphere. Ed. Bruce Robbins. Minneapolis: University of Minnesota Press, 1993. Impreso. 33-41.

Prieto, Adolfo. El discurso criollista en la formación de la Argentina moderna. Buenos

Aires: Editorial Sudamericana, 1988. Impreso.

Rama, Ángel. La ciudad letrada. Hanover: Ediciones del Norte, 1984. Impreso.

Romero, José Luis. Latinoamérica: las ciudades y las ideas. México: Siglo XXI, 1976. Impreso.

Sarmiento, Domingo Faustino. "Bibliotecas populares". Obras Completas. Tomo 30. Buenos Aires: Moreno, 1887-1900. Impreso

"Las novelas". Obras Completas. Tomos 45-46. Buenos Aires: Moreno, 1887-1900. Impreso.

"Velez Sarfield". Obras Completas. Tomo 27. Buenos Aires: Moreno, 1887-1900. Impreso.

Seminario de Historia de la Educación en México del Colegio de México. Historia de la lectura en México. México: Colegio de México y Ediciones del Ermitaño, 1988. Impreso.

Slater, Candace. Stories on a String: The Brazilian Literatura de Cordel. Berkeley: University of California Press, 1982. Impreso.

Subercaseaux, Bernardo. Historia del libro en Chile. Santiago: Editorial Andrés Bello, 1993. Impreso.

__ Fin de siglo: la época de Balmaceda. Modernización y cultura en Chile. Santiago: Editorial Aconcagua, 1988. Impreso.

Sunkel, Guillermo. Razón y pasión en la prensa popular: un estudio sobre cultura popular, cultura de masas y cultura política. Santiago: ILET, 1985. Impreso.

The Conflict between Church and State in Latin America. Ed. Frederick B. Pike. Nueva York: Knopf, 1964. Impreso.

Torre Revello, José. El libro, la imprenta y el periodismo en América durante la dominación española. México: Universidad Nacional Autónoma de México, 1991. Impreso.

Vicuña Mackenna, Benjamín. "La novela en Chile: El ideal de un calavera". El Mercurio 4 de enero de 1864. Reproducido en Silva Castro, Raúl. Alberto Blest Gana. Santiago: Imprenta Universitaria, 1941. Impreso. 